\title{
Frequency of HER2/neu Overexpression in Gastrointestinal Adenocarcinomas: An Immunohistochemical Study in A Tertiary Care Hospital
}

\author{
Gayathri Devi Parasa and Ruth Prasanna Mark* \\ Dept of Pathology, GSL Medical college, Rajamahendravaram- Andhra Pradesh, India
}

\begin{abstract}
Background: As per the data available in the literature, a wide range of HER2neu protein expression in gastric and colorectal adenocarcinomas was reported in various studies world wide. Even though HER2neu over expression has a poor prognosis in these tumours, there is an increased demand for HER2neu study in the laboratories because of the availability of targeted therapy like Transtuzumab. Aim of the study was to determine the frequency of HER2neu protein overexpression in gastrointestinal adenocarcinomas. We studied innunohistochemical expression of HER2neu in a total of 71 cases of gastrointestinal adenocarcinomas.
\end{abstract}

Methods: This was a study done on 71 cases of gastrointestinal adenocarcinomas diagnosed in the pathology laboratory of a tertiary care hospital. Both small biopsies and resection specimens were included. Paraffin blocks and hematoxylin eosin stained sections of these cases were retrieved from the files. Sections were cut from the paraffin blocks and immunohistochemical staining for HER2/neu done. HER2/neu stained sections were examined and findings noted according to the guidelines for HER2neu reporting of gastric biopsies.

Result: HER2/neu positivity (3+ score) on immunohistochemistry was seen in 8 out of 71 gastrointestinal adenocarcinomas (11.26\%). HER2 positivity was $9.52 \%$ (4 out of 42 cases) in gastric adenocarcinomas and $10.2 \%$ (4 out of 39 cases) of colorectal adenocarcinomas.

Conclusion: HER 2 positivity was seen in a significant number of gastrointestinal adenocarcinomas tested, i.e. $9.52 \%$ of gastric adenocarcinomas and $10.2 \%$ of colorectal adenocarcinomas. Overall positivity in gastrointestinal carcinomas was $11.26 \%$. Positivity was seen in cases reported on small biopsies. We did not attempt to study the correlation between HER2 positivity with clinicopathological findings because of the small number of cases studied.

Keywords: HER2 Expression, Immunohistochemistry, Gastric, Colorectal, Adenocarcinomas

\section{Introduction}

Human epidermal growth factor receptor 2 (HER2/neu) belongs to the family of tyrosine kinases that also include epidermal growth factor receptor (EGFR), HER-1, HER-3 and HER-4. HER2 is located on the chromosome 17q21 and encodes a $185 \mathrm{KD}$ transmembrane protein that lacks a natural ligand. Cell proliferation and differentiation pathways, mitogen-activated protein kinase (MAPK) and phosphoinositol 3 kinase, PI3K/AKT pathways are initiated by HER2neu activation. Over expression of HER2neu was seen in many tumours and is associated with poor prognosis in some cancers such as breast and ovary. HER2neu gene amplification and protein over expression were recognised as prognostic and predictive markers for these cancers. There is available targeted therapy i.e. Transtuzumab, a recombinant monoclonal antibody which is used as adjuvant therapy. ${ }^{[1,2,3]}$

HER2 overexpression was also studied in gastrointestinal adenocarcinomas. Phase III randomised trials (Transtuzumab for Gastric Cancer (ToGA) study) revealed that combination of Transtuzumab and chemotherapy showed significant improvement in survival of gastric and gastroesophageal junction carcinomas with overexpression of HER2neu. Trastuzumab was approved for treatment of metastatic adenocarcinomas of stomach and gastroesophageal junction in many countries. ${ }^{[3]} \mathrm{A}$ new immunohistochemistry (IHC) scoring criteria were developed to report HER2neu expression which are slightly different from that of breast carcinoma. ${ }^{[4,5,6]}$ Of 1645 primary colorectal carcinomas in Heppner et al study $1.6 \%$ were HER2 positive. Also these patients showed a poorer overall survival. ${ }^{[7]}$

In the present study we had attempted to study HER2 expression in both gastric and colorectal adenocarcinomas.

\section{Materials and Methods}

This was a Retrospective study. This had been approved by the hospital ethics committee. A total of seventy one gastrointestinal adenocarcinomas were included in this study. Hemotoxylin and eosin stained sections and paraffin 
blocks of all these cases were retrieved from the filing. HER2neu testing by immunohistochemistry was done on all the sections cut from the blocks which had sufficient tissue. Both positive and negative controls were put up. HER2 status was assessed by using monoclonal antibody, antihuman HER2/ErbB2 [EP3]. Results were recorded as per the guidelines for HER2neu reporting according to gastric cancer scoring system of gastric biopsies. Same scoring system was used to assess colorectal biopsies also. All the H\&E stained section were examined and histopathology findings noted. Patients' age, sex and other relevant clinical details were recorded as given in the request forms. IHC scoring used by Ruchoff et al and Hoffman et al was used for scoring the HER2 expression in all the gastrointestinal adenocarcinomas (Table 1)..$^{[1,4,5]}$

The authors had developed different criteria for scoring biopsies and resection specimens. Though this scoring system was developed on gastric and gastroesophageal junction adenocarcinomas, same was used for colorectal adenocarcinomas also. ${ }^{[7]}$

\section{Results}

A total of 71 cases of gastrointestinal adenocarcinomas were studied, that included forty two gastric (including 3 gastroesophageal junction adenocarcinomas) and 39 colorectal adenocarcinomas. Out of 42 gastric adenocarcinomas $40(95.2 \%)$ were small biopsies and 2 $(4.76 \%)$ were gastrectomy specimens. Out of 39 colorectal adenocarcinomas $26(66.66 \%)$ were small biopsies and $13(43.58 \%)$ resection specimens. Age range was 20 to 92 years and 28 to 85 years in gastric and colorectal adenocarcinomas respectively. Average age for gastric adenocarcinoma was 55.4 years and 54.1 years for colorectal carcinomas.

Male to female ratio was 3.6:1 and 1:1.29 in gastric and colorectal adenocarcinomas respectively. Histopathological findings and grading of adenocarcinomas were noted after reviewing the Hematoxylin and eosin stained sections. At both the sites tumours with moderate differentiation were the most followed by poor and well differentiation. Of the gastric adenocarcinomas 25 showed moderate differentiation and 15 were poorly differentiated tumours. There were two cases of signet ring cell adenocarcinomas. Among the colorectal adenocarcinomas 5 were differentiated, 23 moderately differentiated and 7 poorly differentiated tumours. There were also 4 cases of mucinous adenocarcinomas.

Immunohistochemical staining for HER2neu was done and the results were recorded as per gastric cancer scoring system mentioned under material and methods. Out of 42 cases of gastric adenocarcinomas, 4 were HER2neu positive with $3+$ score, equivocal with score $2+$ in 2 cases and rest were negative with score 0 in 34 cases and $1+$ in 2 cases (Figure 1a,b,c,d). Three cases of gastroesophageal junction carcinomas were all negative. Out of 39 colorectal carcinomas 4 cases were HER2neu positive with $3+$ score, equivocal with score $2+$ in one case and negative in 34 cases with score 0 in 32 and $1+$ in 2 (Figure 2 a, b, c, d,) (Table 2 ). All the positive cases were diagnosed on biopsies. None of the resection specimens showed HER2 positivity.

Out of 25 cases of moderately differentiated gastric adenocarcinomas in $8 \%$ cases HER2neu expression was equivocal with $2+$ score and positive in $4 \%$ cases with $3+$ score. Of 17 gastric adenocarcinomas with poor differentiation (including signet ring type) $11.8 \%$ cases were HER2neu positive with $3+$ score and none had $2+$ score (Table 3 ).

Out of 23 moderately differentiated colorectal adenocarcinomas in $4.3 \%$ cases HER2neu expression was equivocal $(2+$ score $)$ and positive in $13 \%$ cases with $3+$ score. Among seven poorly differentiated tumours $14.3 \%$ were HER2neu positive $(3+$ score $)$ and none showed $2+$ score (Table 4).

TABLE 1: HER2NEU Scoring for Gastric Cancer ${ }^{[4,5]}$

\begin{tabular}{|l|l|l|l|}
\hline SCORE & REACTIVITY CHARACTERISTICS & BIOPSY SPECIMEN STAINING PATTERN & $\begin{array}{l}\text { HER2 OVER } \\
\text { EXPRESSION } \\
\text { ASSESSMENT }\end{array}$ \\
\hline 0 & $\begin{array}{l}\text { No reactivity or membranous reactivity in }< \\
10 \% \text { of tumour cells }\end{array}$ & $\begin{array}{l}\text { No reactivity or membranous reactivity in any } \\
\text { tumour cell }\end{array}$ & Negative \\
\hline $1+$ & $\begin{array}{l}\text { Faint/barely perceptible membranous reactivity } \\
\text { in } \geq 10 \% \text { of Tumour cells; cells are reactive } \\
\text { only in part of their membrane }\end{array}$ & $\begin{array}{l}\text { Tumour cell cluster with a faint/barely perceptible } \\
\text { membranous reactivity irrespective of percentage } \\
\text { of tumour cells stained }\end{array}$ & Negative \\
\hline $2+$ & $\begin{array}{l}\text { Weak to moderate complete, basolateral, } \\
\text { or lateral membranous reactivity in } \geq 10 \% \text { of } \\
\text { Tumour cells }\end{array}$ & $\begin{array}{l}\text { Tumour cell cluster with a weak to moderate } \\
\text { complete, basolateral, or lateral membranous } \\
\text { reactivity irrespective of percentage of tumour } \\
\text { cells stained }\end{array}$ & Equivocal \\
\hline
\end{tabular}




\begin{tabular}{|c|c|c|c|}
\hline SCORE & REACTIVITY CHARACTERISTICS & BIOPSY SPECIMEN STAINING PATTERN & $\begin{array}{l}\text { HER2 OVER } \\
\text { EXPRESSION } \\
\text { ASSESSMENT }\end{array}$ \\
\hline $3+$ & $\begin{array}{l}\text { Moderate to strong complete, basolateral, } \\
\text { or lateral membranous reactivity in } \geq 10 \% \text { of } \\
\text { tumour cells }\end{array}$ & $\begin{array}{l}\text { Tumour cell cluster with a strong complete, } \\
\text { basolateral, or lateral membranous reactivity } \\
\text { irrespective of percentage of tumour cells stained }\end{array}$ & Positive \\
\hline
\end{tabular}

TABLE 2: HER2/NEU STATUS IN GASTRIC AND COLORECTAL ADENOCARCINOMAS

\begin{tabular}{|c|c|c|}
\hline & STOMACH $(n=42)$ & COLON(n=39) \\
\hline HER2/neu status & 34 & 32 \\
\hline 0, negative & 02 & 02 \\
\hline $1+$, negative & 02 & 01 \\
\hline $2+$, equivocal & 04 & 04 \\
\hline $3+$, positive & $9.5 \%$ & $10.2 \%$ \\
\hline
\end{tabular}

TABLE 3 CORRELATION OF HER2NEU EXPRESSION WITH HISTOLOGICAL GRADE OF GASTRIC ADENOCARCINOMA

\begin{tabular}{|l|c|c|c|c|}
\hline \multirow{2}{*}{ HISTOLOGICAL GRADE } & TOTAL NO OF & \multicolumn{3}{|c|}{ HER2NEU SCORE } \\
\cline { 3 - 5 } & CASES & $\mathbf{0 , 1 + \text { negative }}$ & 2+ equivocal & 3+ positive \\
\hline Well differentiation & 0 & 0 & 0 & 0 \\
\hline Moderate differentiation & 25 & $22(88 \%)$ & $02(8 \%)$ & $01(4 \%)$ \\
\hline Poor differentiation & 17 & $15(88.2 \%)$ & 0 & $02(11.8 \%)$ \\
\hline Total & $\mathbf{4 2}$ & $\mathbf{3 7 ( 8 9 \% )}$ & $\mathbf{0 2}(\mathbf{4 . 7} \%)$ & $\mathbf{0 3}(\mathbf{7 . 1} \%)$ \\
\hline
\end{tabular}

TABLE 4: CORRELATION OF HER2NEU EXPRESSION WITH HISTOLOGICAL GRADE AND TYPE OF COLONIC ADENOCARCINOMA

\begin{tabular}{|c|c|c|c|c|}
\hline \multirow{2}{*}{ HISTOLOGICAL TYPE AND GRADE } & \multirow{2}{*}{$\begin{array}{l}\text { TOTAL NO OF } \\
\text { CASES }\end{array}$} & \multicolumn{3}{|c|}{ HER2NEU SCORE } \\
\hline & & $0,1+$ negative & $2+$ equivocal & $3+$ positive \\
\hline Well differentiated adenocarcinoma & 05 & $05(100 \%)$ & 0 & 0 \\
\hline $\begin{array}{l}\text { Moderately differentiated } \\
\text { adenocarcinoma }\end{array}$ & 23 & $19(82.6 \%)$ & $01(4.3 \%)$ & $03(13 \%)$ \\
\hline Poorly differentiated adenocarcinoma & 07 & $06(85.7 \%)$ & 0 & $01(14.3 \%)$ \\
\hline Mucinous adenocarcinoma & 04 & $04(100 \%)$ & 0 & 0 \\
\hline Total & 39 & 34 & 01 & 04 \\
\hline
\end{tabular}

TABLE 5: HER 2 EXPRESSION IN GASTRIC ADENOCARCINOMAS, COMPARISON BETWEEN PRESENT STUDY AND OTHER STUDIES

\begin{tabular}{|c|c|c|c|c|c|c|}
\hline \multirow[t]{2}{*}{ NAME OF THE STUDY } & \multirow{2}{*}{$\begin{array}{l}\text { NO OF } \\
\text { CASES } \\
\text { STUDIED }\end{array}$} & \multicolumn{5}{|c|}{$\begin{array}{l}\text { HER2 EXPRESSION (SCORE AND RESULT) IN GASTRIC } \\
\text { ADENOCARCINOMAS }\end{array}$} \\
\hline & & 0 negative & \multicolumn{2}{|l|}{ 1+negative } & 2+equivocal & 3+positive \\
\hline Ling Shan et al ${ }^{[6]}$ & 1463 & \multicolumn{3}{|l|}{$75.8 \%$} & $14.4 \%$ & $9.8 \%$ \\
\hline Raj et al [9] & 58 & \multicolumn{3}{|l|}{$69 \%$} & $7 \%$ * & $24 \%$ \\
\hline Raj Gopal et al [11] & 77 & \multicolumn{2}{|l|}{$61.7 \%$} & $6.7 \%$ & $5 \%$ & $26.37 \%$ \\
\hline Present study & 39 & \multicolumn{2}{|l|}{$80.95 \%$} & $4.76 \%$ & $4.76 \%$ & $9.52 \%$ \\
\hline
\end{tabular}


TABLE 6: HER 2 EXPRESSION IN COLORECTAL ADENOCARCINOMAS, COMPARISON BETWEEN PRESENT STUDY AND OTHER STUDIES

\begin{tabular}{|c|c|c|c|c|c|}
\hline \multirow[t]{2}{*}{$\begin{array}{l}\text { NAME OF THE } \\
\text { STUDY }\end{array}$} & \multirow[t]{2}{*}{$\begin{array}{l}\text { NO OF CASES } \\
\text { STUDIED }\end{array}$} & \multicolumn{4}{|c|}{$\begin{array}{l}\text { HER2 EXPRESSION (SCORE AND RESULT) IN COLORECTAL } \\
\text { ADENOCARCINOMAS }\end{array}$} \\
\hline & & 0 negative & 1+negative & 2+equivocal & 3+positive \\
\hline Farzand et al ${ }^{[10]}$ & 31 & $25.8 \%$ & $19.35 \%$ & $22.58 \%$ & $32.25 \%$ \\
\hline Heppner et al ${ }^{[7]}$ & 1645 & $97.3 \%$ & $3.42 \%$ & $2.1 \%$ & $0.5 \%$ \\
\hline Schuell et al ${ }^{[1]}$ & 77 & $70 \%$ & $26 \%$ & $1 \%$ & $3 \%$ \\
\hline Present study & 39 & $82.05 \%$ & $5.12 \%$ & $2.56 \%$ & $10.25 \%$ \\
\hline
\end{tabular}

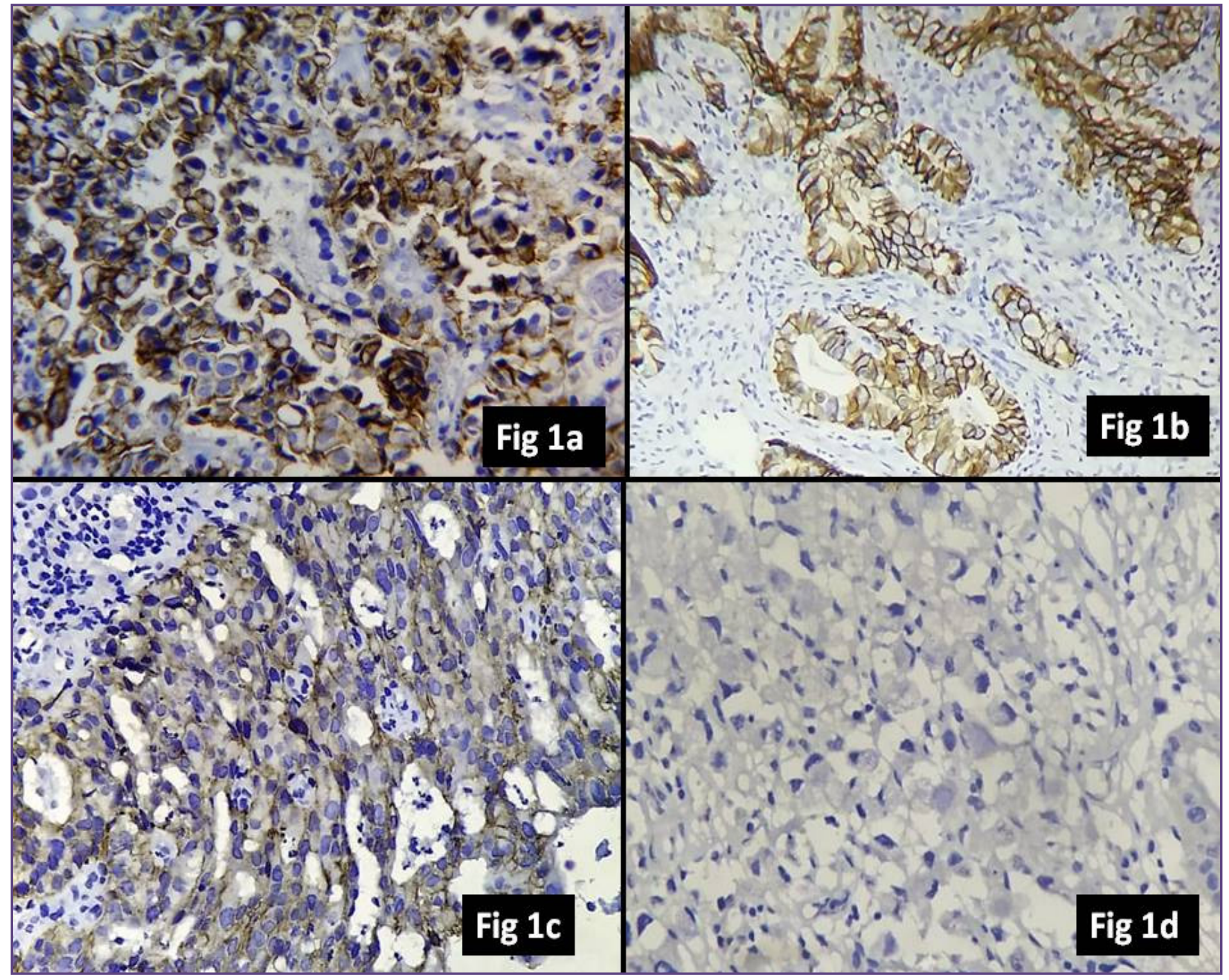

Fig. 1: HER2 expression: gastric adenocarcinomas. 1a) Poorly differentiated adenocarcinoma: positive (3+), strong membranous staining [40x] 1b) positive $(3+)$, strong basolateral as well as complete membranous positivity [10x], 1c) equivocal $(2+)$, weak to moderate basolateral membrane staining [40x] 1d) Signet ring cell carcinoma, negative (0) [40x]. 


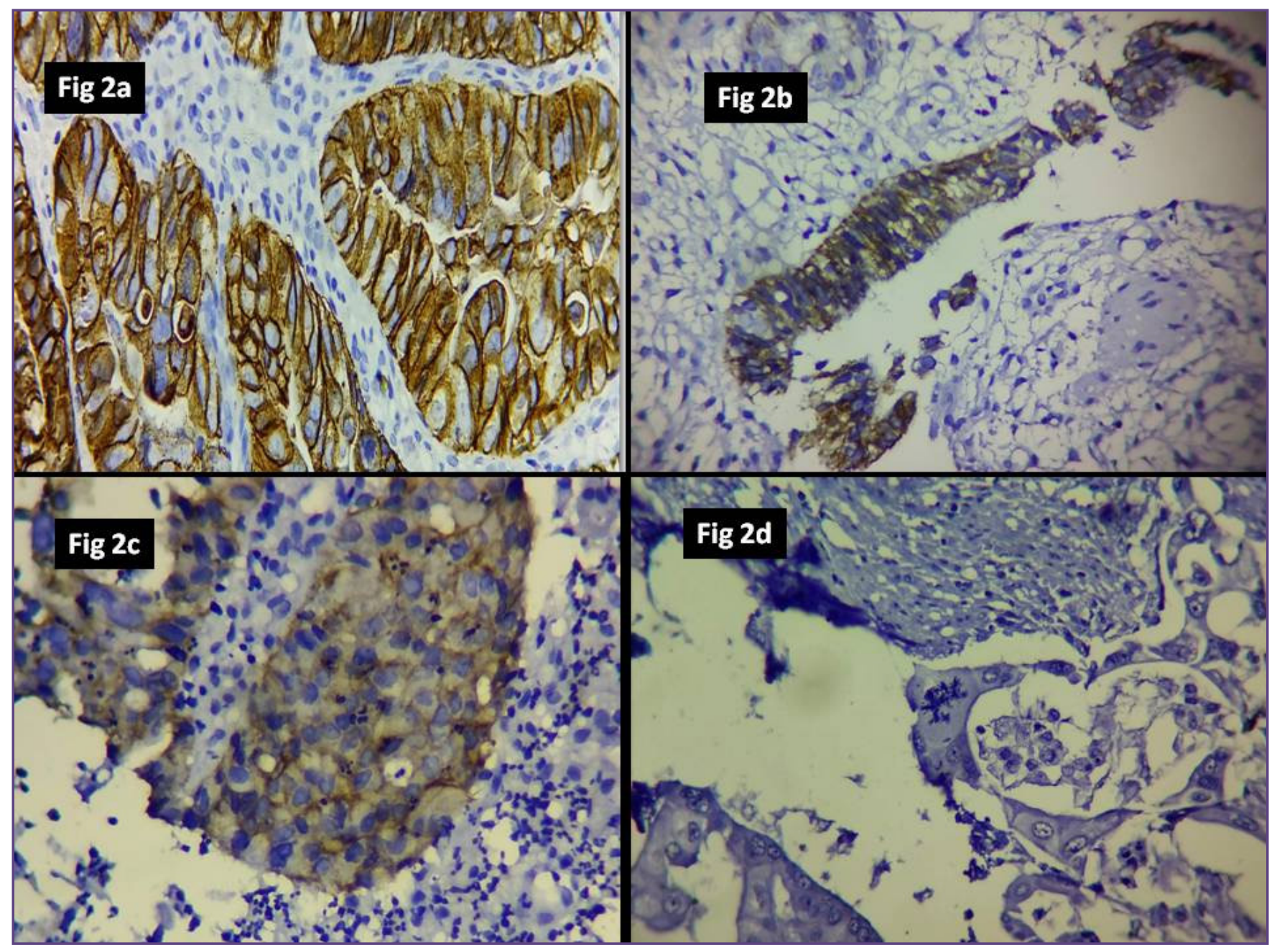

Fig. 2: HER2 expression: colorectal adenocarcinoma. 2a) Moderately differentiated adenocarcinoma, strong complete membranous staining (3+), 2b) Strong lateral and basal membrane staining, positive (3+), 2c) Faint to weak basolateral staining, negative $(1+), 2 d)$ No staining, negative ( 0 ).

\section{Discussion}

In this study total of 71 cases of gastrointestinal adenocarcinomas were included, forty two were gastric and thirty nine were colorectal. Average age was 55.4 years (range 20-92 years) for gastric and 54.1 years (age range was 28 to 85 years) for colorectal adenocarcinomas. In Farzand $\mathrm{S}$ et al ${ }^{[6]}$ study mean age was 52.8 and 46.5 years for gastric and colorectal adenocarcinomas respectively, which was less as compared to the present study. Incidence of gastric adenocarcinomas was high among males and a slight female preponderance was seen in colorectal adenocarcinomas. Similar findings were noted by Aditi R

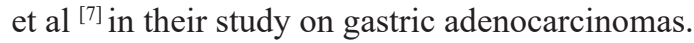

As per the studies available a wide range of HER2/ neu expression was observed in gastrointestinal adenocarcinomas. ${ }^{[6,7,8,9,10,11,12,13,14]}$ In ToGA trial HER2 over expression of $3+$ positivity was seen in $10.4 \%$ for resected samples. ${ }^{[2]}$ For colorectal adenocarcinomas $3+$ positivity on IHC was seen in $0.5 \%$ cases. In the present study $3+$ positivity on IHC was seen in $9.5 \%$ of gastric adenocarcinomas and $10.2 \%$ of colorectal adenocarcinomas; which was almost similar to that of findings in Shan et al study. However 2+ positivity was observed in $4.76 \%$ of gastric and $2.56 \%$ of colorectal adenocarcinomas respectively. Comparison of HER2 expression on immunohistochemistry of the present with other studies is as follows (Table $5 \&$ Table 6)

There were varied opinions regarding the association of HER2 expression with site, adenocarcinoma subtype and its differentiation. Shan et al reported higher rates of HER2 positivity in GEJ adenocarcinomas than in stomach carcinoma. ${ }^{[6]}$ We had only three cases of GEJ adenocarcinomas in this study, all of which were negative 
for HER2. Raj Gopal et al found significant association between HER 2 positivity and intestinal subtype and also moderate differentiation. ${ }^{[11]}$ In present study we did not find such association and also no statistical correlation was made with age and sex.

Shan et al in a study of 1463 gastric/gastroesophageal junction adenocarcinomas found strong correlation of HER2 positivity for GEJ location, intestinal subtype and well or moderate differentiation. Higher rates of HER2 over expression in well to moderately differentiated gastric adenocarcinomas was observed by Chao et al and Laura Tafe et al. ${ }^{[6,13,14]}$ Schuell B et al found no relationship between Her2neu expression and tumour differentiation in their studyon colorectal adenocarcinomas. ${ }^{[1]}$ In the present study HER2neu positivity was more frequent in poorly differentiated gastric adenocarcinomas (11.8\%) as compared to moderately differentiated tumours (4\%). Whereas in colorectal adenocarcinomas slight predominance in HER2neu positivity was seen in poorly differentiated tumours $(14.3 \%)$ as compared to moderately differentiated tumours.

In many of the studies $3+$ and $2+$ positivity on IHC was further evaluated and confirmed by FISH or CISH. ${ }^{[8]}$ Due to the lack of availability this was not done in the present study.

In most studies HER2 expression was studied on either gastric or colorectal adenocarcinomas separately. ${ }^{[1,6,7}$, $8,9,11$,$] Very few studies were available on the entire$ gastrointestinal tract adenocarcinomas. ${ }^{[10]}$ In the present study we attempted to study HER2 expression on both gastric and colorectal adenocarcinomas and according to the results HER 2 positivity on immunohistochemistry was $9.4 \%$ in gastric and $10.2 \%$ for colorectal adenocarcinomas. No significant association was found between grade of tumour and HER2 expression. $3+$ and $2+$ positive cases have to be subjected to fluroscence in situ hybridization (FISH) or chromogenic insitu hybridization (CISH) for confirmation. ${ }^{[5,9]}$

There is increased demand for HER2neu testing on gastrointestinal adenocarcinomas because of the survival benefit due to available targeted therapy. As many monoclonal antibodies directed against HER2 were available this can be done routinely in all gastrointestinal adenocarcinomas, not only for the targeted therapy but also as a prognostic tool.

\section{Conclusion}

There is increased demand for HER2neu testing on gastrointestinal adenocarcinomas because of the survival benefit due to available targeted therapy. As many monoclonal antibodies directed against HER2 were available this can be done routinely in all gastrointestinal adenocarcinomas, not only for the targeted therapy but also as a prognostic tool. However this should be done with established standardised protocols.

\section{Acknowledgements}

We would like to thank Dr T. Satya Prakash Venkatachalam, head of the department, pathology for the support and Mr. Maheshwara Chowdary for expert technical help in performing the immunohistochemical staining.

\section{References}

1. Schuell B, Gruenberger T, Scheithauer W, Zielinski Ch, Wrba F. HER 2/neu protein expression in colorectal cancer. BMC Cancer 2006;6:123-127.

2. Van CE, Kang Y, Chung H, Shen L, Sawaki A, Lordick F, et al.Efficacy results from the ToGA trial: A phase III study of trastuzumab added to standard chemotherapy (CT) in first-line human epidermal growth factor receptor 2 (HER2)-positive advanced gastric cancer (GC) J Clin Oncol. 2009;27:15s. (supple;abstr LBA4509)

3. Bang YJ, Van CE, Feyereislova A, Chung HC, Shen L, Sawaki A, et al. Trastuzumab in combination with chemotherapy versus chemotherapy alone for treatment of HER2-positive advanced gastric and gastroesophageal junction cancer (ToGA): a phase 3, open-label, randomized control trial. Lancet. 2010;376:687-97

4. Ruschoff J, Hanna W, Bilous M et al. HER2 testing in gastric cancer: a practical approach. Mod Pathol 2012; 25: 637-50

5. Hofmann M, Stoss O, Shi D, Buttner R, Vijver MVD, Kim W, et al. Assessment of HER2 scoring system for gastric cancer: results from a validation study. Histopathology. 2008;52:797-805

6. Shan L, Ying J, Lu N. HER2 expression and relevant clinicopathological features in gastric and gastroesophageal junction adenocarcinoma in a Chinese population. Diagn Pathol 2013; 8: 76-82

7. Ingold HB, Behrens HM, Balschun K, Haag J, Kruger S, Becker $\mathrm{T}$, et al. HER2/neu testing in primary colorectal carcinoma. Br J Cancer 2014;111:1977-84

8. Sekaran A, Kandagaddala RS, Darisetty S, Lakhtakia S, Ayyagari S, Rao GV, et al. HER2 expression in gastric cancer in Indian population-an immunohistochemistry and fluorescence in situ hybridization study. Indian J Gastroenterol. 2012;31(3):106

9. Aditi R, Aarathi R, Pradeep R, Hemalatha L, Akshatha C, Amar K. HER2 Expression in Gastric Adenocarcinoma-a study in a tertiary care centre in South India. Indian J Surg Oncol 2016;7:18-24

10. Farzand S, Siddique T, Saba K, Bukhari MH. Frequency of HER2/neu overexpression in adenocarcinoma of the gastrointestinal system. World Journal of Gastroenterology : WJG. 2014;20(19):5889-5896 
11. Rajagopal I, Niveditha SR, Sahadev R et al. HER 2 Expression in gastric and gastro-esophageal junction (GEJ) adenocarcinomas. J Clin Diagn Res 2015; 9: EC06-10.

12. Pathmathan N, Geng J, Li W, Nie X, Veloso J, Wang J et al. Human epidermal growth factor receptor 2 status of gastric cancer patients in Asia: results from a large, multicountry study. Asia-Pac J Clin Oncol 2017; 13: 249-260.

13. Chao H, Xue-Yi B, Xing-Zhi N, Shen DP, Shen YY, Liu $\mathrm{H}$, et al. Correlation of human epidermal growth factor receptor 2 expression with clinicopathological characteristics and prognosis in gastric cancer. World $\mathrm{J}$ Gastroenterol. 2013;19:2171-78.

14. Tafe LJ, Janjigian YY, Zaidinski M, Hedvat CV, Hameed MR, Tang LH, et al. Human epidermal growth factor receptor 2 testing in gastresophageal cancer: correlation between immunohistochemistry and fluorescence in situ hybridization. Archives of pathology \& laboratory medicine. 2011;135:1460-65.

*Corresponding author:

Dr M.Ruth Prasanna, MD., Associate Professor, Pathology, GSL Medical college, Rajamahendravaram-533296, Andhra Pradesh, India

Email: prasanna.mark@gmail.com

Financial or other Competing Interests: None. 